\title{
El género Paecilomyces Bainier
}

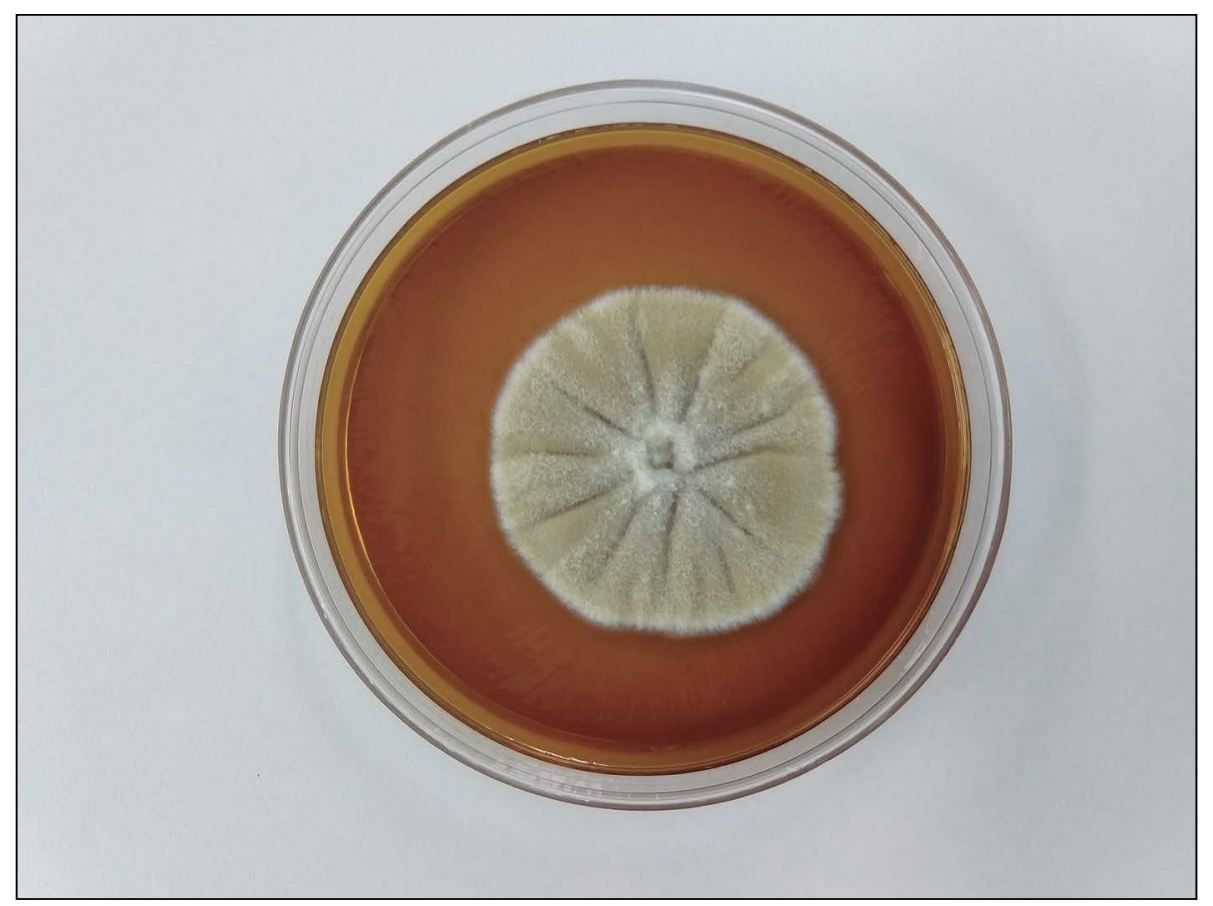

Figura 1. Se observa colonia de color canela de 5 centímetros de diametro a los 7 días de cultivo en agar malta a $30^{\circ} \mathrm{C}$. Especie obtenida de muestra respiratoria de niña con fibrosis quistica.

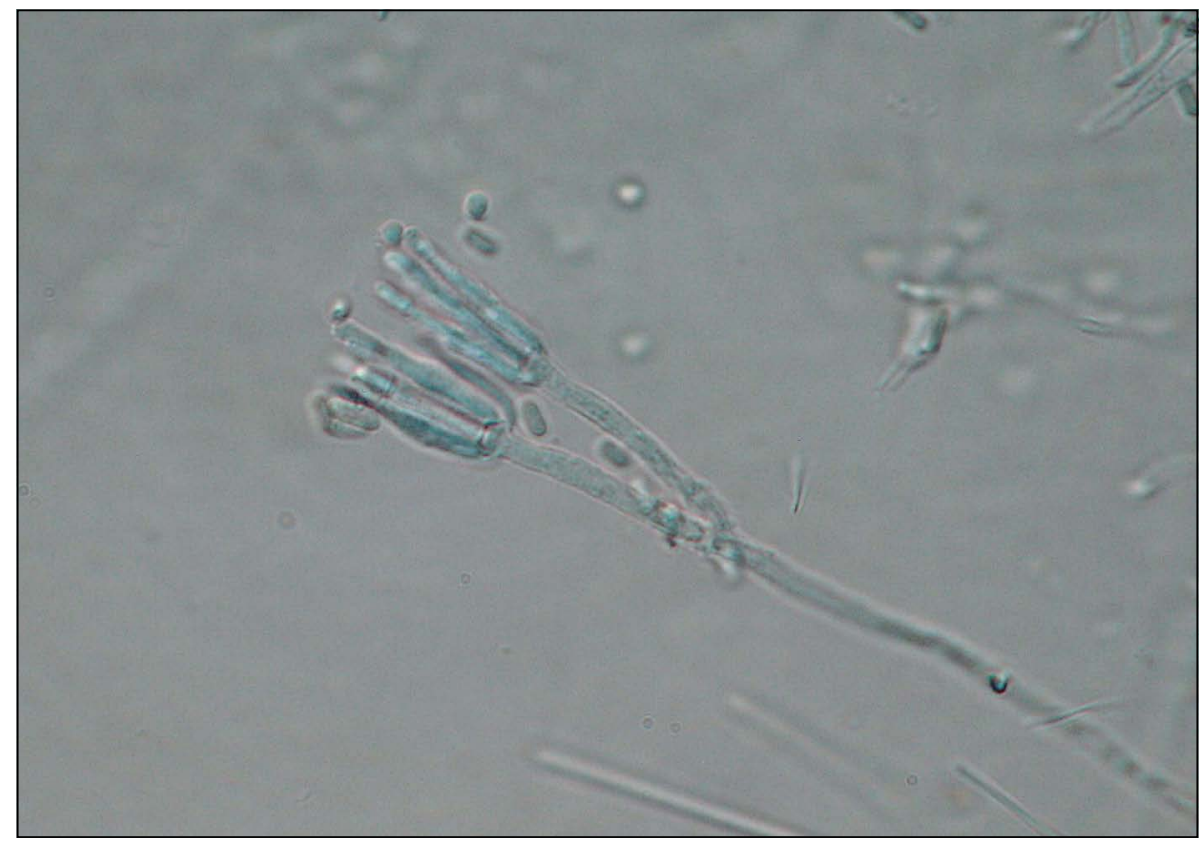

Figura 2. Se observa conidioforos verticilados con fialides cilindricas alargadas. Tinción de lactofenol con azul de aldodón. 100X. 


\section{El género Paecilomyces Bainier}

El género Paecilomyces (Ascomycota, Pezizomycotina, Eurotiales, Trichocomaceae) comprende una gran cantidad de especies ubicuas, cosmopolitas, considerados agentes de biodegradación y de descomposición, además de estar presentes en el suelo, insectos, nematodos, maderas, aire y agua, entre otros sustratos.

Dentro del género Paecilomyces, varias especies han sido reclasificadas en otros géneros, como Chamaeleomyces y Purpureocillium. Este último, con importancia clínica, pues puede causar infecciones en pacientes inmunocomprometidos o con factores de riesgo. También posee la capacidad de formar biopelículas y colonizar materiales como catéteres e implantes, además de contaminar antisépticos de uso clínico.

Considerando ambos géneros, Paecilomyces y Purpureocillium, las especies más comunes encontradas en infecciones humanas son Pur. lilacinum, $P$. variotii, $P$. marquandii, $P$. formosus, $P$. saturatus, $P$. javanicus y $P$. niveus, las que se han descrito en neumonía, osteomielitis, sinusitis, endoftalmitis, otitis, infecciones del tejido blando, peritonitis y onicomicosis.

En relación a la sensibilidad frente a los antifúngicos, se han encontrado importantes diferencias en los perfiles in vitro. Voriconazol, no muestra actividad frente a P. variotii pero sí frente a Pur. lilanicus. Anfotericina B muestra actividad frente a $P$. variotii y no frente a Pur. lilanicus. Por esta razón, la identificación a nivel de especie de los aislados de Paecilomyces / Purpureocillium es primordial para la elección adecuada de una terapia antifúngica.

Descripción de la especie tipo: Paecilomyces variotii.

Macromorfología: Colonias de crecimiento rápido en agar malta, pulverulentas, de colores dorados, amarillentas a café o canela que nunca tienen colores verdes, conidióforos irregulares y termotoleracia hasta $50^{\circ} \mathrm{C}$ (Figura 1).

Micromorfología: Conidióforos irregulares y verticilados de hasta $150 \mathrm{um}$ de largo con 3,5 x 5,5 um de ancho, fialides cilíndricas o dilatadas que terminan en un largo y delgado cuello (lo diferencia de Penicillium) que producen cadenas desordenadas de conidio subesféricos a elipsoidales, de paredes lisas de 3-5 x 2-4 um (Figura 2).

\section{Referencias bibliográficas}

1.- Luangsa-ard J, Houbraken J, van Doorn T, Hong S, Borman A M, Hywel-Jones N L, et al. Purpureocillium, a new genus for the medically important Paecilomyces lilacinus. FEMS Microbiol Lett.2011; 321: 141-9. doi: 10.1111/j.1574-6968.2011.02322.x.

2.- Houbraken J, Verweij P E, Rijs A, Borman A M, Samson R A. Identification of Paecilomyces variotii in clinical samples and settings. J Clin Microbiol.2010; 48: 2754-61. doi: 10.1128/JCM.00764-10.

3.- de Hoog G S, Guarro J, Gené J, Ahmed S, Al-Hatmi A M S, Figueras M J, et al. Atlas of Clinical Fungi, 3rd e-edition. Utrecht / Reus.2019.

Rodrigo Cruz Choappa ${ }^{1}$ y Peggy Vieille ${ }^{1}$ ${ }^{\prime}$ Laboratorio de Micología. Universidad de Valparaiso.

Correspondencia a: Rodrigo Cruz Choappa. Rodrigo.cruz@uv.cl 